\title{
Dating ice cores
}

\author{
JAKOB SCHWANDER
}

Climate and Environmental Physics, Physics Institute, University of Bern, Switzerland; schwander@climate.unibe.ch

\section{Introduction}

An accurate chronology is the basis for a meaningful interpretation of any climate archive, including ice cores. Until now, the oldest ice recovered from a continuous core is that from Dome Concordia, Antarctica, with an estimated age of over 800,000 years (EPICA Community Members, 2004). But the recently recovered cores from near bedrock at Kohnen Station (Dronning Maud Land, Antarctica) and Dome Fuji (Antarctica) compete for the longest climatic record. With the recovery of more and more ice cores, the task of establishing a good common chronology has become increasingly important for linking the findings from the different records. Moreover, in order to create a comprehensive picture of past climate dynamics, it is crucial to aim at a common chronology for all paleo-records. Here the different methods for dating ice cores are summarized.

\section{Layer counting}

Due to the seasonal variation of temperature, sunlight or atmospheric circulation, concentrations of many trace substances or isotopes show cyclic variations in the ice cores. In the ideal case, these annual cycles can be counted many thousand years back in time. Depending on the conditions in the ice (temperature, thinning of layers, etc.), variations are smoothed by diffusion or altered by chemical reactions or clustering. Diffusion can be reversed mathematically to a certain degree by a deconvolution algorithm (Johnsen, 1977), which extends the depth range for layer counting. Yet, there is always a lower limit below which the annual variations are lost. One reason for this is that wind is mixing the snow on the surface by scouring and relocation. Another reason is that the annual variations are already smoothed out when they are compacted to solid ice at the firn-ice transition. Best accuracy for layer counting is obtained by combining different tracers (Fig. 1) (Fuhrer et

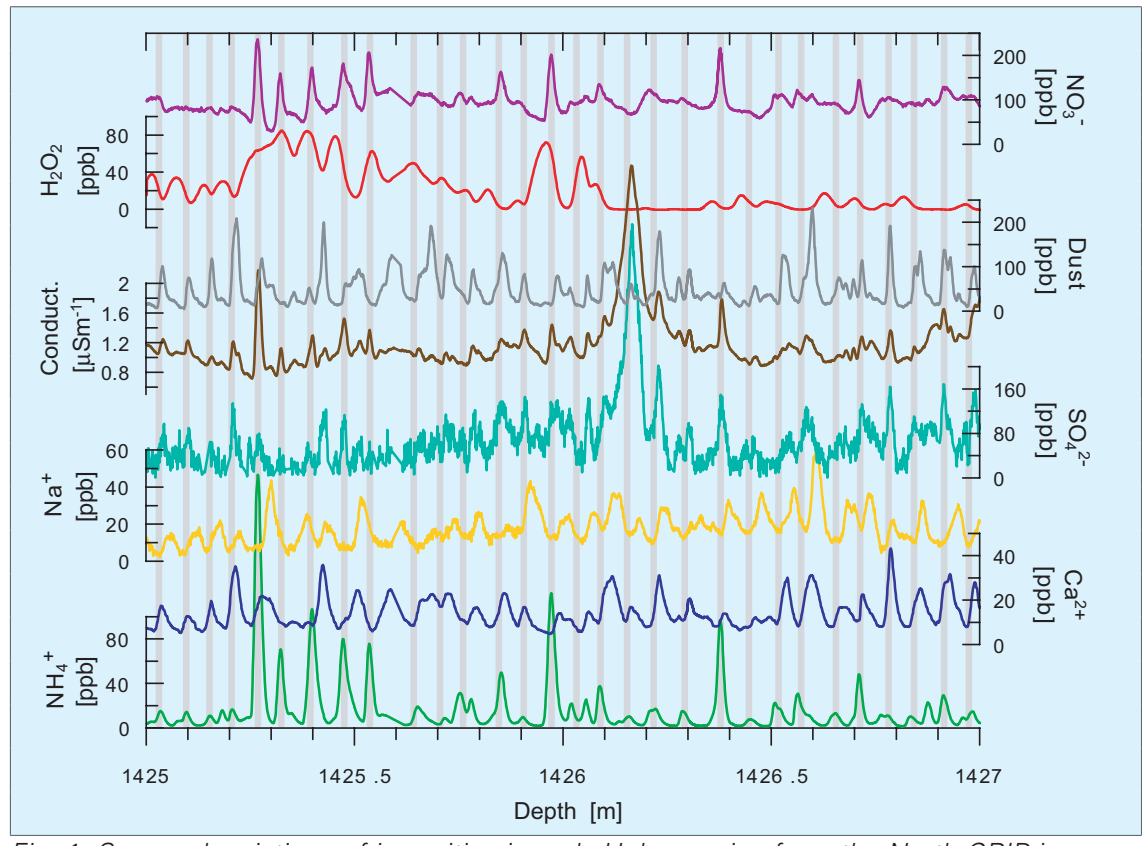

Fig. 1: Seasonal variations of impurities in early Holocene ice from the North GRIP ice core. Summer layers are indicated by grey lines.

al., 1993, Rasmussen et al., 2006). Ideally the counting uncertainty is on the order of $1 \%$.

\section{Ice flow modeling}

Ice is a fluid with an empirical relation between stress and strain rate (power law with an exponent of approx. 3, known as Glen's law (Glen, 1955)). With the knowledge of all material properties and boundary conditions, the plastic deformation of a glacier or ice sheet could be modeled in detail (Fig. 2). However, these boundary conditions and properties are generally poorly known. The bedrock topography is not resolved in sufficient detail and past surface conditions (temperature, precipitation) can only be estimated indirectly. The same holds for the parameters that determine the flow properties, like ice temperature, crystal orientation, impurities and basal sliding. Flow profiles at a certain site can often be approximated by simple flow models that are determined by local parameters, like ice sheet thickness, basal sliding, basal melting, and few parameters to describe the horizontal flow. These parameters are either measured or constrained by age fixpoints. If thinning $\varepsilon_{z}$ at any depth z is assessed with such a model, then one can construct a chronology of the ice if past accumulation rates $\mathrm{a}(\mathrm{z})$ are known.

$\operatorname{age}(z)=\int_{z}^{H} \frac{d z^{\prime}}{\varepsilon_{z^{\prime}} \cdot a\left(z^{\prime}\right)}$

( $\mathrm{H}$ is surface elevation of ice sheet)

The estimate of past accumulation rates is the Achilles' heel of dating by flow models. Such estimates are mostly based on a functional dependence of precipitation and local temperature (estimated from the stable isotope records). There are, however, other causes for variations in past accumulation rates, like changes in circulation or changes in local surface topography. In order to improve the accuracy of the age model, parameters can be constrained by assigning well-dated time horizons to corresponding depths. Such events are, e.g., glacial terminations or minima of Earth's magnetic field that have been dated with best possible accuracy on other paleoarchives (Parrenin et al., 2001). The age uncertainty obtained by flow models depends on the accuracy of accumulation rate estimates (in the order of $20 \%$ ) and on the existence of local flow disturbances. 


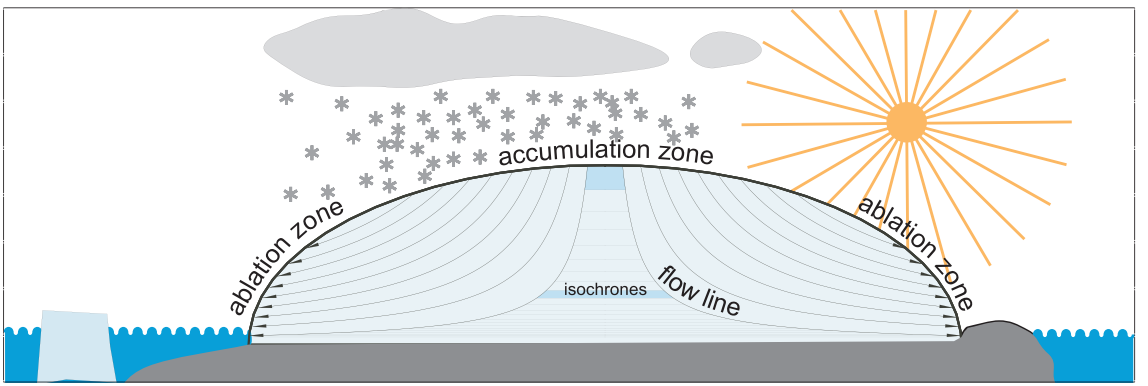

Fig. 2: Cross-section through an idealized ice sheet. Layers are stretched and thinned by plastic flow. The two highlighted layers (blue) comprise the same number of annual layers.

\section{Radiometric dating}

Because both layer counting and flow models may be subject to systematic errors, absolute radiometric clocks are needed. A number of radioactive isotopes have been used to estimate the age of natural ice samples or the occluded air. These include fission products, ${ }^{3} \mathrm{H}$ (Tritium), ${ }^{210} \mathrm{~Pb},{ }^{32} \mathrm{Si},{ }^{39} \mathrm{Ar},{ }^{85} \mathrm{Kr},{ }^{14} \mathrm{C},{ }^{81} \mathrm{Kr},{ }^{36} \mathrm{Cl},{ }^{10} \mathrm{Be}$, and Uranium series. Fission products resulting from nuclear weapon testing in the atmosphere during the 1950s and 60s, can easily be detected by total beta-activity measurements. Other radiometric dating methods have failed to be competitive with current dating tools because the initial concentrations of the radioactive isotopes are too variable. However, these methods remain interesting, e.g., to estimate the age of very old ice near bedrock.

\section{Synchronisation with other paleo-records}

Ice core chronologies often rely on indirect dating, i.e. by comparison with other, better-dated paleo-archives, including other ice cores. In the ideal case, the well-dated record is annually laminated (Hughen et al., 1998, Zolitschka, 1998). Yet, these varved sediments are often affected by hiatuses or do not extend to the present but they can provide valuable information on the duration of climatic events. Other archives are well suited for absolute dating methods, like U/Th-dated speleothems or corals.

The prerequisite for a correlation with ice core records is that events exist in the ice core record that are unequivocally assignable to a synchronous event in the other record. Such events can be volcanic eruptions, Milankovitch-type variations, abrupt climate variations (Dansin the Earth's magnetic field or solar activity, etc. Global records of methane and $\delta^{18} \mathrm{O}_{\text {atm, }}$, for example, have been used to synchronize ice core records from Greenland and Antarctica (Blunier and Brook, 2001).

In the second half of the 19th century, James Croll proposed that the Pleistocene ice ages are caused by periodic changes in the Earth's orbit around the Sun. Milutin Milankovitch improved the astronomical theory, leading to a presently general acceptance of the causality between Earth's orbital parameters and climate variations. There are three astronomical parameters that determine the latitudinal and seasonal variation of insolation on Earth: Precession (periods: 22, 24 kyr), Obliquity (41, 40 kyr), and Eccentricity (404 kyr and several around $100 \mathrm{kyr}$ ).

Tuning to the Milankovitch cycles is accomplished by changing its correlation with the target curve (e.g. summer insolation at a certain latitude) is increased. A shortcoming of the method is the problem of overtuning. Recent orbital tuning work has therefore been as conservative as possible (Karner et al., 2002, Lisiecki and Raymo, 2005). The uncertainty in the phasing between paleo-records and the astronomical cycles is on the order of $5 \mathrm{kyr}$. Ice core records can be correlated to the Milankovitch cycles either directly or indirectly via synchronization, e.g., with marine sediment records (EPICA Community Members, 2004). Direct tuning includes the temperature-sensitive stable isotope ratios of the ice, the $\delta^{18} \mathrm{O}$ of oxygen in the trapped air (Parrenin et al., 2001), and the $\mathrm{O}_{2} / \mathrm{N}_{2}$ ratio (Bender, 2002). Age uncertainties obtained by synchronization techniques vary from one year (e.g.
gaard-Oeschger events), variations the chronology of a record such that historic volcanic signals) to several thousand years.

\section{Age of the gaseous records}

The upper 50-120 m of an ice sheet is made of consolidated snow (firn), permeable to air. Air occluded at the firn-ice transition is therefore substantially younger than the ice. This age difference can be estimated with densification/diffusion models (Schwander et al., 1997). The air at the firn-ice transition is on the order of one to a few decades. The age of the ice at the firn-ice transition spans a large range of a few tens to several thousand years under present conditions, depending mainly on temperature and accumulation rates. Locations with high accumulation rates and relatively high annual temperatures show the smallest ages, while sites in central Antarctica with accumulation rates of a few $\mathrm{cm}$ per year show the largest ages. The difference between the age of the ice and the age of the air has not remained constant over time. Under glacial conditions this age difference was generally several times larger than at present. Due to uncertainties in estimating the accumulation rate and the close-off depth in the past, the error in the age difference is around $10 \%$

\section{REFERENCES}

Bender, M. L., 2002: Orbital tuning chronology for the Vostok climate record supported by trapped gas composition. Earth and Planetary Science Letters, 204: $275-289$.

Blunier, T. and Brook, E. J., 2001: Timing of millennialscale climate change in Antarctica and Greenland during the last glacial period. Science, 291: 109-112.

Johnsen, S. J., 1977: In Proc. of Symp. on Isotopes and Impurities in Snow and Ice, Int. Ass. of Hydrol. Sci., Commission of Snow and Ice, I.U.G.G. XVI, General Assembly, Grenoble Aug.Sept., 1975. IAHS-AISH publication: 210-219.

Johnsen, S. J., Clausen, H. B., Dansgaard, W., Fuhrer, K., Gundestrup, N., Hammer, C. U., Iversen, P., Jouzel, J., Stauffer, B. and Steffensen, J. P., 1992: Irregular glacial interstadials recorded in a new Greenland ice core. Nature, 359: 311-313.

Schwander, J., Sowers, T., Barnola, J.-M., Blunier, T., Malaizé, B. and Fuchs, A., 1997: Age scale of the air in the summit ice: Implication for glacial-interglacial temperature change. Journal of Geophysical Research, 102: 19483-19494.

For full references please consult: www.pages-igbp.org/products/newsletters/ref2006_1.html 